\title{
Incidence, risk factors and prognostic impact of cytomegalovirus infection after heart transplantation
}

\author{
Incidencia, factores de riesgo e impacto pronóstico de la infección por citomegalovirus \\ tras el trasplante cardiaco
}
Elizabet Méndez-Eirín ${ }^{\mathrm{a}, \mathrm{b}}$, Eduardo Barge-Caballero ${ }^{\mathrm{a}, \mathrm{b}}$, María Jesús Paniagua-Martín ${ }^{\mathrm{a}, \mathrm{b}}$, Gonzalo Barge-Caballero, ${ }^{\mathrm{a}, \mathrm{b}}$, David Couto-Mallón ${ }^{\mathrm{a}, \mathrm{b}}$, Zulaika Grille-Cancela ${ }^{\mathrm{a}, \mathrm{b}}$, Paula Blanco-Canosa ${ }^{\mathrm{a}, \mathrm{b}}$, Angelina Cañizares-Castellanos ${ }^{\mathrm{c}}$, Miguel González Barbeito ${ }^{\mathrm{d}}$, Ana Vanesa Aller Fernández ${ }^{\mathrm{e}}$, José Manuel Vázquez-Rodríguez ${ }^{\mathrm{a}, \mathrm{b}}$, María Generosa Crespo- Leiro $^{\mathrm{a}, \mathrm{b}}$

\footnotetext{
${ }^{a}$ Servicio de Cardiología, Complejo Hospitalario Universitario A Coruña, Instituto de Investigación Biomédica de A Coruña (INIBIC), A Coruña, Spain

${ }^{b}$ Centro de Investigación Biomédica en Red de Enfermedades Cardiovasculares (CIBERCV), Instituto de Salud Carlos III, Madrid, Spain

${ }^{c}$ Servicio de Microbiología, Complejo Hospitalario Universitario A Coruña, A Coruña, Spain

${ }^{d}$ Servicio de Cirugía Cardiaca, Complejo Hospitalario Universitario A Coruña, A Coruña, Spain

${ }^{e}$ Servicio de Medicina Intensiva, Complejo Hospitalario Universitario A Coruña, A Coruña, Spain
}

\begin{abstract}
Introduction and objectives. To assess the risk factors of CMV infection after heart transplant (HT) and its influence on long-term prognosis.

Methods. We conducted a retrospective single-centre study of $222 \mathrm{H} \mathrm{T}$ recipients. Risk factors for CMV infection were identified by means of multivariable Cox's regression. Kaplan-Meier analysis and Cox's regression were used to assess the long-term prognostic impact of CMV infection during the first post-transplant year.

Results. Donor-recipient CMV serologic matching (hazard ratio [HR] 1.92, 95\% confidence interval [95\% CI] $1.2-$ $3.09, \mathrm{p}=.007$ ), recipient age (HR 1.02, 95\% CI 1.00-1.1, p=.02), diabetes mellitus (HR 1.86, 95\% CI 1.4-3.05, $\mathrm{p}=.01$ ), pre- transplant circulatory support (HR 1.59,95\% CI 1.06-2.38, $\mathrm{p}=.03$ ) and the use of tacrolimus (HR 1.64, 95\% CI 1.13-2.36, $\mathrm{p}=.009$ ) were independently associated with increased risk of CMV infection. CMV infection during the first year post-HT was not associated with worse transplant outcomes in terms of mortality, incidence of heart failure, cardiac allograft vasculopathy or acute rejection.

Conclusions. CMV infection was not associated with impaired long-term prognosis after HT.
\end{abstract}

\section{Resumen}

Introducción y objetivos. Analizar el impacto pronóstico de la infección por Citomegalovirus (CMV) durante el primer año tras el trasplante cardiaco (TC) y describir factores de riesgo.

Métodos. Se realizó un estudio retrospectivo unicéntrico incluyendo 222 receptores de TC. La identificación de factores de riesgo de infección por CMV se llevó a cabo mediante regresión multivariable de Cox. Mediante los métodos de Kaplan-Meier y Cox se analizó la influencia de la infección por CMV durante el primer año sobre la supervivencia e incidencia de eventos clínicos adversos en el seguimiento a largo plazo.

Resultados. En el análisis multivariante, el estado serológico donante/receptor frente a CMV (hazard ratio [HR] 1,92, intervalo de confianza 95\% [IC 95\%] 1,2-3,09; $p=0007$, la edad del receptor HR 1,02, IC 95\% 1,00-1,1; $p=0,02$ ), la diabetes (HR 1,86, IC 95\% 1,4-3,05; p=0,01), el soporte circulatorio mecánico (HR 1,59, IC 95\% 1,06-2,38; 
$\mathrm{p}=0,03)$ y el uso de tacrolimus (HR 1,64, IC 95\% 1,13-2,36; $\mathrm{p}=0009$, resultaron predictores independientes de infección por CMV post-trasplante. No se detectó una influencia significativa de la infección por CMV durante el primer año post-trasplante sobre la mortalidad, la incidencia de insuficiencia cardiaca, enfermedad vascular del injerto o rechazo agudo.

Conclusiones. La infección por CMV durante el primer año post-trasplante no se asoció a un peor pronóstico a largo plazo.

Keywords

Heart transplant; Cytomegalovirus; Outcomes; Survival.

Palabras clave

Trasplante cardiaco; Citomegalovirus; Pronóstico; Supervivencia

\section{Introduction}

Cytomegalovirus (CMV) is the most common viral pathogen in heart transplant (HTx) recipients. 1 In these patients, CMV infection can lead to direct cytotoxic effects, such as viral syndrome or tissueinvasive disease, as well as causing indirect effects, such as an increased risk of graft rejection and vasculopathy, which are the consequences of complex immunomodulatory and pro-inflammatory mechanisms triggered by the virus. 2

The relationship between CMV and the indirect effects on the transplanted organ is based on studies carried out over the years, with different methodologies and that include patients receiving different prophylaxis schemes. Therefore, it is difficult to draw definitive conclusions about the relationship between the CMV and these indirect effects.

The purpose of this study is to analyse the incidence and risk factors of CMV infection after HTx, as well as to assess the impact of CMV infection during the first post-transplant year on the long-term prognosis.

\section{Methods}

\section{Study population}

We conducted a retrospective observational study based on the historical cohort of patients who received an orthotopic HTx in our site from 2001 to 2011. Infant recipients and those who died during the postoperative hospitalisation immediately after HTx were excluded.

\section{Immunosuppression protocol}

Induction therapy with basiliximab is the treatment of choice in our site. Maintenance immunosuppressive therapy consists of a combination of a calcineurin inhibitor (cyclosporine or tacrolimus), an antiproliferative agent (mycophenolate mofetil or azathioprine) and steroids. mTOR inhibitors (everolimus or sirolimus) are used, at the discretion of the medical team, in selected patients with graft vascular disease (GVD), renal failure and/or neoplasms.

\section{Diagnosis of cytomegalovirus infection and definitions}

The assay used for the virological monitoring of CMV was the pp65 antigenemia until December 2007 and since then it has been the quantitative real time polymerase chain reaction (PCR). The determination of antigenemia or CMV PCR was performed coinciding with the protocol endomyocardial biopsies, or in the case of a clinical suspicion of CMV infection. 
"CMV infection" is defined as the detection of viral proteins using an antigenemia assay or CMV DNA by PCR, with any level of positivity and regardless of symptoms. When the infected subject also presented symptoms or clinical signs compatible with systemic involvement (viral syndrome) or visceral involvement it was considered as "CMV disease".

The patients were divided into two groups in relation to the risk of having CMV infection or CMV disease, depending on the donor/recipient serological status (D/R). The "high risk" group was defined as the group consisting of $\mathrm{D}+/ \mathrm{R}-$.

\section{Antiviral therapy}

All the patients received chemoprophylaxis with ganciclovir or valganciclovir during the first month posttransplantation. In patients at high risk for CMV infection, the duration of chemoprophylaxis was prolonged to a minimum of 3 months.

At follow-up, early therapy with ganciclovir or valganciclovir was administered to the recipients who presented asymptomatic CMV infection, and to the recipients who received intravenous steroid boluses for suspected acute rejection, if they had also had previous CMV disease or if they belonged to the high risk group.

\section{Outcomes}

The patients were monitored from the date of the HTx until their death or, failing that, until March 2015. The principal study outcome was total mortality after HTx. Other outcomes analysed were hospitalisation for heart failure and the incidence of GVD and acute rejection.

The causes of death were collected from autopsy reports and death certificates. Death due to cardiac cause was defined as that caused by heart failure, myocardial ischaemia or arrhythmia, including those attributable to acute rejection, GVD and any sudden unexplained death.

GVD was defined by the presence of any stenosis $\geq 50 \%$ of the luminal diameter in any of the 3 main epicardial coronary vessels or their branches, detected by coronary angiography.

"Hospitalisation for heart failure" was defined as any hospitalisation for clinical heart failure in the presence of a left ventricular ejection fraction $<45 \%$, determined by an echocardiogram or ventriculogram, or in the presence of restrictive physiology of the graft, determined by an echocardiogram or an invasive haemodynamic study. 3

"Acute graft rejection" was defined as any episode of acute cellular rejection of grade $\geq 2 \mathrm{R}, 4$ symptomatic or not, or an episode of acute humoral rejection of pAMR grade $\geq 1,5$ accompanied by clinical heart failure and/or systolic graft dysfunction, or any episode of suspected acute rejection not proven by biopsy that would have required treatment with intravenous steroid boluses, plasmapheresis, intravenous immunoglobulin or thymoglobulin.

\section{Statistic analysis}

Categorical variables are expressed as percentages and continuous variables as mean \pm standard deviation. The differences between groups were compared using the Chi-squared or t-Student tests, as required.

The incidence rates of infection and/or CMV disease were determined taking into account two different time periods: follow-up during the first post-transplant year, and follow-up beyond the first posttransplant year. The $95 \%$ confidence interval (95\% CI) estimate of the incidence rate of infection/CMV disease was performed using the exact Clopper-Pearson method. 
For the study of risk factors for CMV infection, an analysis of univariate and multivariate risk factors was performed using Cox regression models. The risk of CMV infection attributed to each variable obtained by this method is expressed by the hazard ratio (HR) together with the $95 \% \mathrm{CI}$ of the HR. The multivariate analysis used the "backward steps" method, and in the initial step it included all the factors that showed a univariate association with the risk of CMV infection with a $p$-value as $p<0.10$. As exit criteria (p-out) for the successive exclusion of multivariate variables, a p-value was established as $p<0.05$ In all other statistical analyses performed, the level of statistical significance was set at a $p$-value of $\mathrm{p}<0.05$

Survival and cumulative probability curves of adverse clinical events were constructed using the KaplanMeier method, and they were compared using the logarithmic range scale.

In order to control the influence of potential confusion biases on the statistical association between CMV infection during the first year after HTx and survival and incidence of clinical events in the late follow-up ( $>1$ year), we performed a multivariate adjustment using a Cox regression analysis. In addition to CMV infection during the first year the multivariate model included other covariates that were considered as potential confounding factors due to their association with the incidence of CMV infection in our cohort (age of the recipient, diabetes mellitus, era of the transplant and treatment with tacrolimus). The "pre-HTx mechanical circulatory support" variable, which also showed an association with the risk of CMV infection during the first year after the HTx, was not included in the adjustment model. This was because clinical reasoning suggests that, although this variable has a recognised prognostic impact on immediate mortality after HTx, the impact of this past clinical event on the prognosis of patients in late follow-up (>1 year) is irrelevant. Finally, the "high risk for CMV infection" variable was not included in the adjustment model either, because, given the relationship of dependency between this variable and the occurrence of CMV infection, we consider that it could not be treated in any case as a confounder, but rather as an intermediate.

The statistical analysis was carried out using the SPSS version 21.0 package (SPSS, Chicago, Illinois) and the application Epidat 4.1, Consellería de Saúde, Xunta de Galicia [Health Council, Government of Galicia, Spain).

\section{Results}

\section{Study population}

During the study period, 286 HTx were performed in our site. Twenty-five child recipients and 39 patients who died during postoperative hospitalisation after HTx were excluded from the study, so the sample analysed was finally made up of 222 patients. The average follow-up was $7.8 \pm 3.5$ years

Table 1 summarises the baseline characteristics of the patients depending on whether they had CMV infection or not in the first post-transplant year. 
Table 1. Baseline clinical characteristics of the study patients.

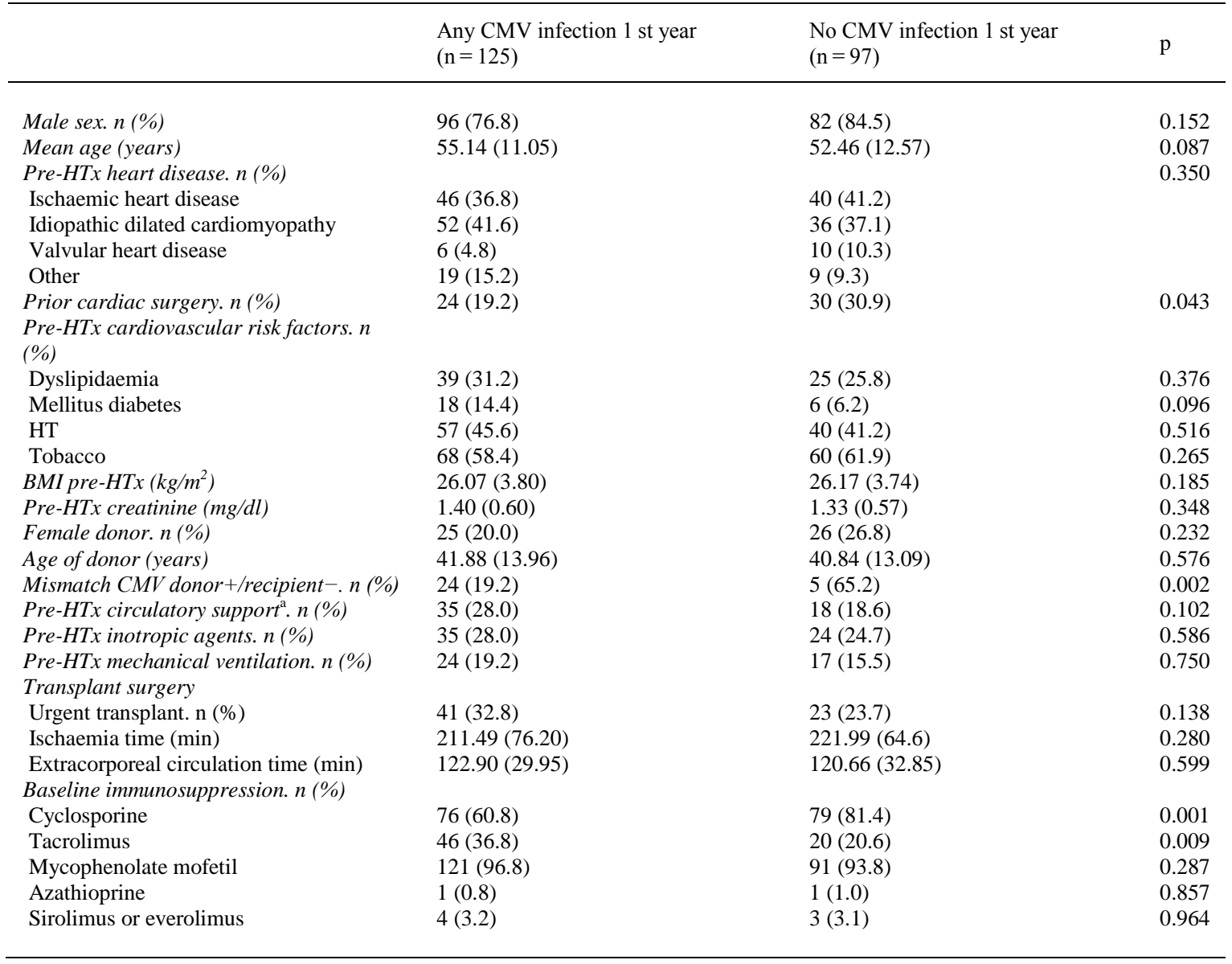

The values express absolute numbers and percentages or mean (standard deviation).

CMV: cytomegalovirus; HT: arterial hypertension; BMI: body mass index; HTx: heart transplant.

${ }^{a}$ Intra-aortic balloon counterpulsation, extracorporeal membrane oxygenation or ventricular assistance.

\section{Incidence of cytomegalovirus infection}

During the first year after HTx, 7 patients died, so the mean follow-up of the global cohort during this period was 359.13 days. During this follow-up, 112 patients presented a total of 178 episodes of CMV infection, of which 157 were asymptomatic infections and 21 were symptomatic disease. This resulted in a total incidence rate of CMV infection during the first year after HTx of 81.5 episodes per 100 patientyears (95\% CI: 69.9-99.4).

Throughout the late follow-up ( $>1$ year after HTx), 27 of the 215 surviving recipients presented a total of 55 episodes of CMV infection, of which 42 corresponded to asymptomatic infections and 13 to CMV disease. With a mean late follow-up of 7.1 years, these figures resulted in a total incidence rate of CMV infection after the first year post-transplant of 3.6 episodes per 100 patients and year of follow-up (95\% CI: $2.7-4.7)$.

Table 2 shows the incidence rates of early and late CMV infection after HTx. 
Table 2. Incidence rate of CMV infection after transplantation.

\begin{tabular}{|c|c|c|c|c|}
\hline & \multicolumn{2}{|l|}{ Early } & \multicolumn{2}{|l|}{ Late } \\
\hline & $\begin{array}{l}\text { Incidence rate (episodes } / 100 \\
\text { patient-years) }\end{array}$ & $95 \% \mathrm{CI}$ & $\begin{array}{l}\text { Incidence rate (episodes } / 100 \\
\text { patient-years) }\end{array}$ & $95 \% \mathrm{CI}$ \\
\hline Asymptomatic CMV infection & 71.9 & $61.1-84.0$ & 2.8 & $1.9-3.7$ \\
\hline CMV disease & 9.6 & $5.9-14.7$ & 0.9 & $0.5-1.6$ \\
\hline Total (infection + disease) & 81.5 & $69.9-99.4$ & 3.6 & $2.7-4.7$ \\
\hline
\end{tabular}

CMV: cytomegalovirus; $95 \%$ CI: $95 \%$ confidence interval.

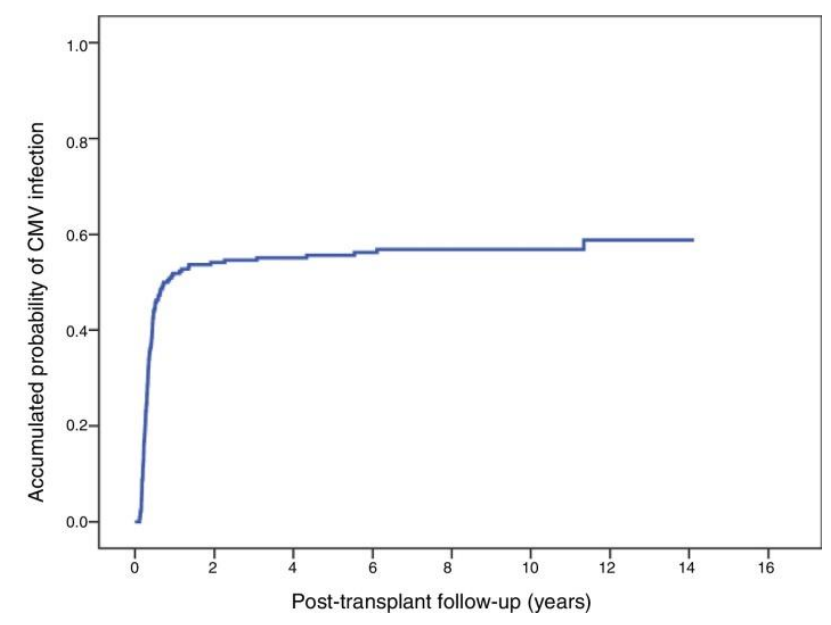

Fig. 1. Cumulative probability of CMV infection in post-transplant follow-up. CMV: cytomegalovirus.

\section{Risk factors for cytomegalovirus infection}

Table 3 shows the results of the Cox analysis used to investigate the risk factors for CMV infection after HTx. Using the multivariate model, independent risk factors $(\mathrm{p}<0.05)$ for CMV infection were selected, namely: the mismatch $\mathrm{D}+/ \mathrm{R}$ - with regards to the CMV serology; age; diabetes mellitus; the use of tacrolimus; and mechanical circulatory support prior to HTx. After the multivariate adjustment, the era of the transplant was not an independent predictor of the risk of CMV infection. 
Table 3. Univariate and multivariate analysis of risk factors for CMV infection after cardiac transplantation.

\begin{tabular}{|c|c|c|c|c|c|c|}
\hline \multirow[b]{2}{*}{ Variable } & \multicolumn{3}{|c|}{ Univariate analysis } & \multicolumn{3}{|c|}{ Multivariate analysis $^{\mathrm{a}}$} \\
\hline & HR & $95 \% \mathrm{CI}$ & $\mathrm{p}$ & HR & $95 \% \mathrm{CI}$ & $\mathrm{p}$ \\
\hline Recipient age & 1.014 & $0.990-1.030$ & 0.092 & 1.021 & $1.00-1.039$ & 0.016 \\
\hline Prior cardiac surgery & 0.656 & $0.420-1.024$ & 0.064 & 0.650 & $0.408-1.034$ & 0.067 \\
\hline Mellitus diabetes & 2.164 & $1.325-3.533$ & 0.002 & 1.862 & $1.135-3.053$ & 0.022 \\
\hline Mismatch CMV donor+/recipient- & 1.883 & $1.204-2.945$ & 0.006 & 1.922 & $1.196-3.088$ & 0.010 \\
\hline Pre-HTx circulatory support & 1.525 & $1.032-2.254$ & 0.034 & 1.586 & $1.059-2.376$ & 0.030 \\
\hline Era of the HTx (2001-2006 vs. 2007-2011) & 1.540 & $1.081-2.195$ & 0.017 & 1.123 & $0.742-1.699$ & 0.584 \\
\hline Tacrolimus use & 1.735 & $1.205-2.498$ & 0.003 & 1.635 & $1.133-2.360$ & 0.010 \\
\hline
\end{tabular}

CMV: cytomegalovirus; HR: hazard ratio; 95\% CI: 95\% confidence interval; HTx: heart transplant.

${ }^{a}$ Multivariate analysis which includes variables with $\mathrm{p}<0.10$ in univariate analysis.

\section{Survival after transplant}

Among the 215 patients who survived at least one year after HTx, 45 (20.9\%) patients died and 3 (1.4\%) received a second HTx during late follow-up. Death was of cardiac origin in $20(44.4 \%)$ patients and of non-cardiac origin in $25(55.6 \%)$. We do not find any relevant differences in the distribution of long-term causes of death in relation to the presence or absence of CMV infections during the first year after HTx.

Fig. 2 shows the survival curves beyond the first year after HTx according to the presence or absence of CMV infection during the first year. No statistically significant differences were observed between both groups $(\mathrm{p}=0.565)$. The adjusted HR for any cause mortality during late follow-up for patients with or without CMV infection was 1.14 (95\% CI: 0.63-2.09) (Table 4).

Table 4. Summary of study events.

\begin{tabular}{lllll}
\hline Events. n (\%) & $\begin{array}{l}\text { CMV infection 1 st } \\
\text { year }(\mathrm{n}=109)\end{array}$ & $\begin{array}{l}\text { No CMV infection 1 st } \\
\text { year }(\mathrm{n}=106)\end{array}$ & Univariate HR & Multivariate HR $^{\mathrm{a}}$ \\
\hline $\begin{array}{l}\text { Death from any cause } \\
\begin{array}{l}\text { Hospitalization due to heart } \\
\text { failure }\end{array}\end{array}$ & $23(21.1)$ & $22(20.8)$ & $1.19(0.66-2.15)$ & $1.14(0.63-2.09)$ \\
$\begin{array}{l}\text { Graft Vascular Disease } \\
\text { Acute graft rejection }\end{array}$ & $19(17.4)$ & $17(16.0)$ & $1.69(0.86-3.32)$ & $1.58(0.79-3.16)$ \\
& $19(17.4)$ & $19(17.9)$ & $1.05(0.55-1.98)$ & $0.90(0.47-1.74)$ \\
\end{tabular}

CMV: cytomegalovirus; HR: hazard ratio.

${ }^{a}$ Covariates included in the multivariate model: age of the recipient, diabetes mellitus, era of transplantation and use of tacrolimus. 

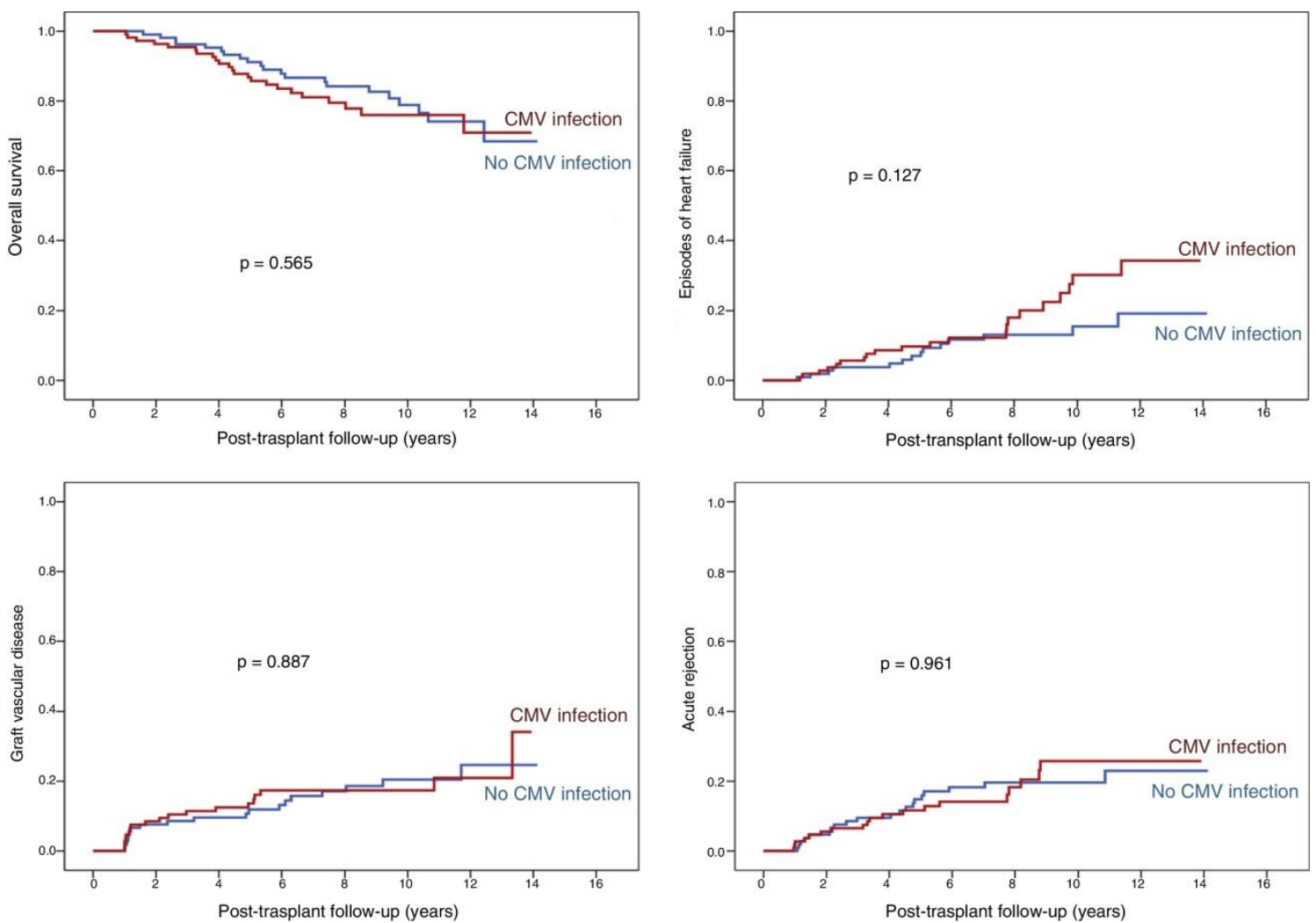

Fig. 2. Cumulative incidence curves of events stratified by the presence of any CMV infection during the first post-transplant year. CMV: cytomegalovirus.

\section{Other outcomes}

Among the 215 patients who survived at least one year after HTx, 39 (18.1\%) patients were hospitalised for heart failure during late follow-up. No significant differences were observed regarding this event between patients with or without CMV infections during the first year $(p=0.127)$. Neither were statistically significant differences observed in the multivariate analysis (adjusted HR 1.58; 95\% CI: 0.79-3.16) (Table 4).

Nor were statistically significant differences observed with respect to the cumulative incidence of angiographic GVD or acute graft rejection depending on the presence or absence of CMV infection during the first year after HTx (Fig. 2). 


\section{Discussion}

In this study we have evaluated the incidence and risk factors of CMV infection in a historical cohort of $222 \mathrm{H} \mathrm{Tx}$ recipients. In addition, we have studied the potential effect of CMV infection during the first post-transplant year on the long-term prognosis, without evidencing a significant influence in terms of survival, hospitalisation for heart failure, GVD or acute graft rejection.

The results of our study show that asymptomatic CMV infection is a frequent finding after HTx, with results similar to the findings of a recent prospective study, in which the incidence of CMV infection in the first year was $43 \%, 6$ and similar to those of other classic studies in which the incidence of CMV infection ranged from 38 to $53 \% .7,8$ In our series, a decrease in the incidence of asymptomatic CMV infection was detected after the first post-transplant year, but it is necessary to point out that incidence of late CMV infection could actually be higher than estimated in our analysis, given that, according to the protocol of our site, the monitoring of CMV infection in asymptomatic patients is less exhaustive after the first year post-HTx, when it is only performed routinely in patients who are hospitalised for other reasons.

The progression to CMV disease was low in our study, which could be explained by the widespread use of universal prophylaxis, which has been shown to reduce the risk of CMV disease, 9 as well as the use of early therapy, which implies the periodic monitoring of patients and the administration of antiviral drugs in those with evidence of CMV replication to prevent the development of symptomatic disease.10 A relevant aspect of our cohort is that the presence of severe or fatal CMV disease was exceptional, and no case of mortality attributable to CMV infection was observed.

The principal risk factor associated with the development of CMV infection both in our study and in previously published studies11 is the donor and recipient serological status versus CMV at the time of the HTx, with the combination of seropositive donor and seronegative recipient being associated with a higher risk. The risk that the recipient develops CMV disease in the $\mathrm{D}+/ \mathrm{R}-$ situation is estimated at higher than $50 \%$ if preventive measures are not taken.12

Our study also suggests a significant increase in the risk of CMV infection with the use of tacrolimus. Since its introduction in the therapeutic arsenal, calcineurin inhibitors have become the standard treatment for immunosuppression in the HTx recipient patient, and in recent years, tacrolimus has become the main immunosuppressant rather than cyclosporine. However, its greater immunosuppressive potency could lead to a higher incidence of severe infections. It has been shown that tacrolimus at conventional doses does not have the ability to reactivate latent CMV, but it can favour its replication speed by suppressing the host's antiviral immune response.13, 14

Diabetes mellitus was another factor associated with an increased risk of post-transplant CMV infection in our series. The association between diabetes and the risk of infection is widely recognised, but there is no consistent evidence of a specific causal link with the CMV infection, and data relating infection and diabetes in the HTx literature are very limited. In 2003, Marelli et al.15 observed that diabetic patients presented a significant increase in the risk of infection, including bacterial, viral and fungal infections, compared to non-diabetic ones. However, in a later study16 whose objective was to evaluate the prognostic impact of diabetes after HTx, no significant differences were detected in the incidence rates of CMV infection in patients with or without a diagnosis of diabetes prior to the HTx.

Similar to that observed in the study of Durante et al.,17 our study also associated the advanced age of the HTx recipient with a significant increase in the risk of CMV infection. A hypothetical explanation for this result is that, normally, there is more flexibility in the chemoprophylaxis schemes against CMV in older patients, compared to in younger patients, which could favour the development of CMV infection in this age group. In addition, advanced age is associated with a deterioration of the cellular immune response, which represents the most important defence mechanism against CMV infection, which could therefore increase the risk of infection in this population. 
Another of the risk factors associated with the development of post-transplant CMV infection in our study was the use of mechanical circulatory support devices prior to HTx. This variable constitutes a marker of a critical clinical condition of the recipient at the time of the intervention. Critical patients frequently present associated conditions such as therapeutic instrumentation, vital organ dysfunction or malnutrition, which affect the proper functioning of the immunological mechanisms and, therefore, favour infection. In addition, these patients frequently present renal failure, and it is common clinical practice in our environment to defer the start of prophylactic treatment against CMV for several days or even weeks, with the intention of avoiding its potential nephrotoxic effect.

Finally, it should be noted that in our study we have detected a certain "era effect" in the incidence of CMV infections. The infections are more frequent among transplanted patients in a more recent time period. This effect can be attributed, in the first place, to the change in the diagnostic methodology. Our programme included the performance of the CMV plasma PCR as a reference test for the detection of this germ in December 2007, while in the previous era the detection was performed using pp65 antigenemia, which is less sensitive than the new technique. However, the era of the transplant lost its statistical influence on the incidence of CMV infections when this variable was introduced in a multivariate model along with other risk factors for CMV infection that are also more frequent among patients with more recent transplants, such as baseline treatment with tacrolimus, age, diabetes and mechanical circulatory support. This fact could indicate that this apparent secular increase in the incidence of CMV infections not only has to do with the change in diagnostic methodology, but also in a change in the clinical profile of the recipient, who is more susceptible to presenting this kind of infectious complication in the current era.

The principal finding of our study is that the CMV infection during the first year after HTx is not associated with a worse long-term prognosis in terms of survival and graft dysfunction. No significant impact of the CMV infection has been observed during the first year after HTx on mortality, including cardiac, or on hospitalisations for heart failure. It is necessary to point out that in our study we have considered the hospitalisation event due to heart failure in a complementary way to the most classic events, that is GVD and acute rejection, whose validity depends largely on the performance of endomyocardial biopsies or coronary angiograms in patients who are asymptomatic. In the studied cohort, carrying out periodic coronary angiograms for the follow-up of GVD was irregular, so the analysis of this event is subject to certain limitations. However, hospitalisation due to heart failure is a reasonable substitute of the GVD and the rejection, since most cases are secondary to these entities.

Most of the studies published in literature have focused on evaluating the association between the CMV infection and the incidence of GVD, since this is the major determinant of patient and graft survival after HTx. In a systematic review of observational studies published in 2012,18 it was concluded that although there is an ample amount of literature that evaluates the association between CMV and the development of GVD, the available evidence is not consistent, due to the limited number of patients included in the studies, the inclusion of heterogeneous populations, inadequate follow-up of patients, or the use of different definitions of CMV infection or GVD.

Our results regarding the effect of CMV infection on the incidence of long-term GVD disagree with the findings described in 2 recent studies in which both the asymptomatic infection and the CMV disease proved to be independent predictors of long-term GVD development.19, 20 It is important to highlight that both studies included patients from the 1990s, when the immunosuppression regimens used were different from the current ones, as were the monitoring techniques and the prophylaxis schemes against CMV. It is also necessary to point out that the protocol of our site promotes the routine and widespread use of universal chemoprophylaxis and early therapy, which could explain the low incidence of symptomatic infections which are less severe, and the absence of a clear unfavourable prognostic effect of the CMV reactivations. 
Another of the most studied aspects has been the role of CMV infection in the pathogenesis of acute graft rejection. It is necessary to specify that in our analysis only episodes of late acute rejection have been considered, since it is not possible to correlate in the timeline the rejection and CMV infection during the first year. Our study has not revealed a significant impact of CMV infection during the first year after HTx over the incidence of late acute graft rejection. Similar to that previously described with the GVD, the CMV's role in the appearance of acute rejection also continues to be a topic of debate, due to the lack of conclusive data. Although we have abundant papers that supports this association,21, 22 there are other studies in which no difference was found in the incidence and severity of rejection in HTx recipients with and without CMV infection.23 The discrepancies between these results must also be interpreted in the context of a significant heterogeneity of the populations studied, as well as variations in the CMV detection techniques or the chemoprophylaxis regimens.

This study presents a series of limitations. Given its retrospective nature, it is exposed to the selection and information biases inherent in this type of research. In addition, given its character of one site, its results cannot be directly extrapolated to other populations. The sample size of the study is intermediate (222 patients), which may have caused the statistical power of some of the analyses performed to be insufficient to demonstrate the clinically relevant differences as statistically significant.

Throughout the follow-up period different techniques were used to monitor the CMV infection: pp65 antigenemia was the technique used until December 2007 and since then quantitative real-time PCR has been used, which is a more sensitive technique for CMV detection. This fact may have conditioned the increased incidence of CMV infections observed in transplanted patients in the most recent era of our cohort (2007-2011). However, the era of the transplant did not continue as an independent predictor of the risk of CMV infection when this condition was included in a multivariate model along with other risk factors for CMV infection that were also more frequent among patients with more recent transplants, such as baseline treatment with tacrolimus, age, diabetes and mechanical circulatory support.

Finally, coronary angiography was used for the diagnosis of GVD in our study instead of intravascular ultrasound, which is the most sensitive tool for the detection of this pathology, so the incidence of GVD could be underestimated. In addition, this incidence could also be underestimated due to the fact that not all patients had a coronary angiogram at follow-up. For this reason, in our study we have considered the hospitalisation due to heart failure event, since the GVD is a questionable event because it depends on the performance of coronary angiograms in patients who are asymptomatic, and our database does not allow it to be analysed very rigorously. However, hospitalisation for heart failure is a good substitute for GVD, since most cases are secondary to this entity.

In conclusion, in the study cohort, the asymptomatic CMV infection was a frequent complication during the first year after HTx, and this result is similar to that reported in previous publications. However, in a context of widespread use of universal chemoprophylaxis and early therapy, we have observed a low rate of progression to CMV disease. The mismatch of donor and recipient regarding the serological status versus $\mathrm{CMV}$, the age of the recipient, diabetes mellitus, pre-transplant circulatory support and immunosuppression with tacrolimus were identified as independent risk factors for CMV infection after HTx. CMV infection during the first year after HTx was not associated with a worse long-term prognosis in terms of survival, hospitalization for heart failure, GVD or acute graft rejection.

\section{Conflict of interests}

The authors declare no conflict of interest. 


\section{References}

1. D. van de Beek, W.K. Kremers, J.L. Del Pozo, R.C. Daly, B.S. Edwards, C.G.A. McGregor, et al. Effect of infectious diseases on outcome after heart transplant. Mayo Clin Proc, 83 (2008), pp. 304-308

2. L. Potena, H.A. Valantine. Cytomegalovirus-associated allograft rejection in heart transplant patients. Curr Opin Infect Dis, 20 (2007), pp. 425-431

3. M.R. Mehra, M.G. Crespo-

Leiro, A. Dipchand, S.M. Ensminger, N.E. Hiemann, J.A. Kobashigawa, et al. International Society for Heart and Lung Transplantation working formulation of a standardized nomenclature for cardiac allograft vasculopathy-2010. J Heart Lung Transplant. (2010), pp. $717-727$

4. S. Stewart, G.L. Winters, M.C. Fishbein, H.D. Tazelaar, J. Kobashigawa, J. Abrams, et al. Revision of the 1990 working formulation for the standardization of nomenclature in the diagnosis of heart rejection. J Heart Lung Transplant, 24 (2005), pp. 1710-1720

5. J. Kobashigawa, M.G. Crespo-

Leiro, S.M. Ensminger, H. Reichenspurner, A. Angelini, G. Berry, et al. Report from a consensus conference on antibody-mediated rejection in heart transplantation. J Heart Lung Transplant (2011), pp. 252-269

6. J.F. Delgado, N. Manito, L. Almenar, M. Crespo-Leiro, E. Roig, J. Segovia, et al. Risk factors associated with cytomegalovirus infection in heart transplant patients: a prospective, epidemiological study. Transpl Infect Dis., 13 (2011), pp. 136-144

7. G.J. Boland, C. Ververs, R.J. Hené, G. Jambroes, R.A. Donckerwolcke, G.C. de Gast. Early detection of primary cytomegalovirus infection after heart and kidney transplantation and the influence of hyperimmune globulin prophylaxis. Transpl Int, 6 (1993), pp. 34-38

8. J. Niubó, J.L. Pérez, J.T. Martínez-Lacasa, A. García, J. Roca, J. Fabregat, et al. Association of quantitative cytomegalovirus antigenemia with symptomatic infection in solid organ transplant patients. Diagn Microbiol Infect Dis, 24 (1996), pp. 19-24

9. E.M. Hodson, M. Ladhani, A.C. Webster, G.F.M. Strippoli, J.C. Craig. Antiviral medications for preventing cytomegalovirus disease in solid organ transplant recipients. Cochrane Database Syst Rev, 28 (2013), Article CD003774

10. D.R. Snydman, A.P. Limaye, L. Potena. Zamora MR. Update and review: state-of-the-art management of cytomegalovirus infection and disease following thoracic organ transplantation. Transplant Proc, 43 (2011), pp. S1-S17

11. C. da Cunha-

Bang, S.S. Sørensen, M. Iversen, H. Sengeløv, J.G. Hillingsø, A. Rasmussen, et al. Factors associated with the development of cytomegalovirus infection following solid organ transplantation. Scand J Infect Dis, 43 (2011), pp. 360-365

12. R.H. Rubin. Cytomegalovirus in solid organ transplantation. Transpl Infect Dis, 3 (Suppl 2) (2001), pp. 1-5

13. J.A. Fishman, R.H. Rubin. Infection in organ-transplant recipients. N Engl J Med, 338 (1998), pp. 1741-1751

14. U. Fuchs, G. Tenderich, A. Zittermann, F. Szabados, K. Minami, R. Koerfer. Clinical outcome of heart transplant recipients receiving tacrolimus with or without mycophenolate mofetil. Clin Transplant, 20 (2006), pp. 450-456

15. D. Marelli, H. Laks, B. Patel, R. Kermani, A. Marmureanu, J. Patel, et al. Heart transplantation in patients with diabetes mellitus in the current era. J Heart Lung Transplant, 22 (2003), pp. 1091-1097

16. R. Klingenberg, C. Gleissner, A. Koch, P.A. Schnabel, F.-U. Sack, R. Zimmermann, et al. Impact of pre-operative diabetes mellitus upon early and late survival after heart transplantation: a possible era effect. J Heart Lung Transplant, 24 (2005), pp. 1239-1246

17. E. Durante-Mangoni, R. Andini, D. Pinto, D. Iossa, R. Molaro, F. Agrusta, et al. Effect of the immunosuppressive regimen on the incidence of cytomegalovirus infection in 378 heart transplant recipients: A single centre, prospective cohort study. J Clin Virol, 68 (2015), pp. $37-42$

18. J.R. Braga, I.S.O. Santos, M. McDonald, P.S. Shah, H.J. Ross. Factors associated with the development of cardiac allograft vasculopathy--a systematic review of observational studies. Clin Transplant, 26 (2012), pp. E111-24

19. J.F. Delgado, A.G. Reyne, S. de Dios, F. López-Medrano, A. Jurado, R.S. Juan, et al. Influence of cytomegalovirus infection in the development of cardiac allograft vasculopathy after heart transplantation. J Heart Lung Transplant, 34 (2015), pp. 1112-1119

20. Johansson, R. Andersson, V. Friman, N. Selimovic, L. Hanzen, S. Nasic, et al. Cytomegalovirus infection and disease reduce 10-year cardiac allograft vasculopathy-free survival in heart transplant recipients. BMC Infect Dis, 15 (2015), p. 582 
21. M.T. Grattan, C.E. Moreno-Cabral, V.A. Starnes, P.E. Oyer, E.B. Stinson, N.E. Shumway. Cytomegalovirus infection is associated with cardiac allograft rejection and atherosclerosis. JAMA, 261 (1989), pp. 3561-3566

22. M. Stern, H. Hirsch, A. Cusini, C. van Delden, O. Manuel, P. Meylan, et al. Cytomegalovirus serology and replication remain associated with solid organ graft rejection and graft loss in the era of prophylactic treatment. Transplantation, 98 (2014), pp. 10131018

23. P.G. Stovin, T.G. Wreghitt, T.A. English, J. Wallwork. Lack of association between cytomegalovirus infection of heart and rejection-like inflammation. J Clin Pathol, 42 (1989), pp. 81-83 